\title{
Rapid Preoperative Preparation for Thyroidectomy of a Severely Hyperthyroid Patient with Graves' Disease who Developed Agranulocytosis
}

\author{
Daveric Pagsisihan, Aimee Andag-Silva, Olivia Piores-Roderos, Ma. Ailsa Escobin \\ Department of Internal Medicine, De La Salle University Medical Center, Philippines
}

\begin{abstract}
Preoperative preparation of the hyperthyroid patient for thyroidectomy is imperative to avoid perioperative complications due to severe thyrotoxicosis. The mainstay of preparation is the administration of anti-thyroid drugs (ATD). When ATDs cause adverse reactions, an alternative regimen to prepare the patient for definitive management is crucial. We present the case of a 35-year-old Filipino female with Graves' disease who developed methimazole-induced agranulocytosis. She refused to undergo radioactive iodine (RAI) therapy. She was admitted for thyroidectomy with elevated thyroid hormone levels. She was rapidly prepared for thyroidectomy using high-dose steroid, beta-adrenergic blocker, propylthiouracil (PTU) and Lugol's solution. The patient's free thyroxine level decreased after 8 days of treatment, without complications. She then underwent an uneventful subtotal thyroidectomy. In conditions with very limited options, although contraindicated, administration of another ATD may be the last alternative for patients who developed agranulocytosis.
\end{abstract}

Key words: hyperthyroidism, thyroidectomy, agranulocytosis, iodine

\section{INTRODUCTION}

Hyperthyroidism affects approximately $2 \%$ of women and $0.2 \%$ of men. ${ }^{1}$ In the Philippines, thyroid disorders and goiters are highly prevalent. The 2008 Philippine Thyroid Disorder Prevalence Study (PhilTiDeS 1) showed that the prevalence of overt hyperthyroidism was $0.61 \%$, while that of subclinical hyperthyroidism was higher at $5.33 \% .^{2}$

There are 3 methods of treatment for Graves' disease in current practice: surgery, RAI therapy and ATDs. Thyroidectomy is preferentially performed in patients with compressive symptoms or large goiters; relatively low uptake of radioactive iodine; suspected or documented thyroid malignancy; concomitant hyperparathyroidism; moderate to severe active Graves' ophthalmopathy; allergies, intolerance, non-compliance or adverse drug reactions to ATDs; and unwillingness to undergo RAI therapy. ${ }^{3}$ Thyroidectomy is performed after achieving a euthyroid state to prevent the occurrence of thyroid storm post-operatively.3,4 Conventional preoperative preparation of patients who are to undergo thyroidectomy includes administration of ATDs before surgery. A euthyroid state is usually achieved in 4 to 6 weeks. ${ }^{5}$ In cases complicated by severe adverse reactions to ATDs, preoperative preparation can be difficult, and in rare instances, unorthodox.
We report the case of a Filipino woman with Graves' disease who developed agranulocytosis with methimazole. She was rapidly prepared for thyroidectomy using high-dose PTU, high dose steroid, beta-adrenergic blocker and Lugol's solution.

\section{CASE}

A 35-year-old Filipino female was admitted at our institution for uncontrolled Graves' disease. She presented with a 5-month history of palpitations, hyperhidrosis, easy fatigability, weight loss, tremors, exophthalmos and goiter. A previous consultation 2 months before admission revealed a suppressed thyroid stimulating hormone (TSH) level $(<0.06 \mu \mathrm{IU} / \mathrm{mL}$, normal value $0.27-3.75)$, elevated free thyroxine (FT4) (83.12 pmol/L, normal value 11.50-23.00) and elevated free triiodothyronine (FT3) (41.99 pmol/L, normal value 2.5-5.8). She was treated with methimazole (MMI) $30 \mathrm{mg} /$ day PO and propranolol $60 \mathrm{mg} /$ day PO. After one month, she developed agranulocytosis, manifesting with high grade fever, weakness, abdominal pain and diarrhea. She was admitted at another private institution with an absolute neutrophil count (ANC) of $79.5 \times 10^{-9}$ cells/L. She was given broad-spectrum antibiotics, granulocyte-colony stimulating factor, steroid and propranolol. She was discharged afebrile and improved after 6 days, with an ANC of $718 \times 10^{-9}$ cells/L. After refusing RAI therapy, she was advised to undergo thyroidectomy for definitive management.

Corresponding author: Daveric A. Pagsisihan, MD

De La Salle University Medical Center

Gov. D. Mangubat Avenue, Dasmariñas

Cavite-4114, Philippines

E-mail:cir_evad@yahoo.com 
At the time of admission, she denied palpitations, hyperhidrosis, hyperdefecation and easy fatigability. On examination, her blood pressure, heart rate and respiratory rate were $110 / 70 \mathrm{~mm} \mathrm{Hg}, 87$ beats/minute and 20 cycles/minute respectively. She was also afebrile. Exophthalmos, finger tremors and hyperreflexia were noted. The thyroid gland was diffusely enlarged, soft, nontender, with no bruit and palpable nodules. The rest of the physical examination findings were unremarkable. Initial diagnostic examinations revealed normal serum sodium and potassium levels. Two-dimensional echocardiography showed concentric left ventricular hypertrophy with good overall left ventricular systolic function, mild mitral and tricuspid regurgitation, 2+ aortic sclerosis with aortic insufficiency, Doppler evidence of left ventricular relaxation abnormality, with an ejection fraction of $74 \%$ (normal value 55.0-77.0). She was given oral dexamethasone $4 \mathrm{mg} /$ day, propranolol $160 \mathrm{mg} /$ day and propylthiouracil (PTU) $450 \mathrm{mg} /$ day. Two days later, she developed steroid-induced post-prandial hyperglycemia, for which she was given voglibose $0.2 \mathrm{mg}$ PO twice daily. Complete blood count showed leukocytosis (26.6 x 10-9 cells) with segmenter predominance (0.89). FT4 (42.29 $\mathrm{pmol} / \mathrm{L})$ and FT3 (6.42 pmol/L) remained elevated, prompting an increase in oral PTU to $600 \mathrm{mg} /$ day. On the $5^{\text {th }}$ hospital day, Lugol's solution became available and was given at 5 drops every 6 hours (20 drops/day). On the $8^{\text {th }}$ hospital day, FT4 decreased to $26.25 \mathrm{pmol} / \mathrm{L}$.

She then underwent right total thyroidectomy and left subtotal thyroid lobectomy with isthmusectomy under general anesthesia. Intraoperatively, esmolol $10 \mathrm{mg}$ IV was given to prevent arrhythmia and was continued as a continuous drip postoperatively. The surgical procedure was uneventful. Post-operative calcium was $2.0 \mathrm{mmol} / \mathrm{L}$ (normal value 2.10-2.55), prompting initiation of oral calcium supplements. Dexamethasone and propranolol were gradually down-titrated. She was discharged on the $11^{\text {th }}$ hospital day, 4 days post-thyroidectomy. Her discharge medications included voglibose $0.2 \mathrm{mg}$ BID, ciprofloxacin $1 \mathrm{~g} /$ day and a calcium supplement. Voglibose was decreased and eventually discontinued during outpatient follow-up.

\section{DISCUSSION}

Hyperthyroidism is associated with hemodynamic changes, including increased cardiac output, cardiac contractility and heart rate, and decreased peripheral resistance that are related to both the direct cardiostimulatory effects of thyroid hormones and increased oxygen consumption. ${ }^{6}$ It is for these reasons that proper treatment is required.

Thyroidectomy is one of the treatment options for hyperthyroidism. However, thyroid crisis, injury to the recurrent laryngeal nerve, parathyroid injury, and postoperative bleeding are serious complications that are closely related to the adequacy of preoperative preparation. ${ }^{7}$ The goal of preparation is to achieve a euthyroid state. ${ }^{7,8}$ Conventionally, this can be achieved by administration of ATDs, typically using PTU or MMI. Patients are usually rendered euthyroid in 4 to 6 weeks using these medications. , $^{4}$

Our patient underwent thyroidectomy for definitive management of Graves' disease, which could not be safely and adequately managed with prolonged ATD treatment because of agranulocytosis. This rare adverse effect of ATDs has a reported incidence of $0.1-0.5 \%$, with no difference between MMI and PTU.9-11,12

Our case highlights two important points. First, we used high dose PTU for our patient's preoperative preparation to control her hyperthyroidism despite developing MMIinduced agranulocytosis in the previous month. Following agranulocytosis, it is contraindicated to use another ATD since cross-reactivity between PTU and MMI may be as high as $50 \% .3,10$ The mechanism of the development of ATD-induced agranulocytosis is still uncertain. It is thought to be mediated by 2 pathogenetic mechanisms, that of an immune-mediated process and direct intoxication. ${ }^{9}$ Complement-dependent IgM and antigranulocyte antibodies have been demonstrated through immunofluorescence and cytotoxicity assays in patients who developed PTU-induced agranulocytosis. ${ }^{13-17}$ Whether these possible mechanisms also hold true for MMI is still for investigation.

We considered the absence of strong and convincing evidence that PTU- and MMI-induced agranulocytosis are mediated by similar molecular mechanisms, the risk of developing thyroid storm intraoperatively with uncontrolled hyperthyroidism, and most importantly, the lack of alternative treatment for control of hyperthyroidism. Although contraindicated, we still opted to give PTU as a short-course regimen, alongside with corticosteroid, beta-adrenergic blocker and iodine to rapidly prepare her for thyroidectomy. While not generally recommended, serial complete blood count was done to monitor her response to PTU. Tajiri et al successfully identified $78 \%$ of granulocytopenia cases before the onset of symptoms by periodically checking blood counts. ${ }^{12}$ Nakamura et al. also demonstrated that despite the sudden onset of agranulocytosis in many cases, some patients show a gradual decline in granulocyte count on serial determination. ${ }^{9}$ Management was done with informed consent from the patient. She was closely monitored as an in-patient while taking PTU. She was rapidly prepared since the risk of another episode of agranulocytosis is higher the longer an ATD is given.9,11

Second, we used iodine in the form of Lugol's solution as part of our patient's preoperative regimen. Iodine is effective in lowering the metabolic rate of hyperthyroid patients and alleviating thyrotoxic symptoms, as described by Plummer in 1922.7 It blocks thyroid hormone synthesis by inhibiting iodine organification and release, while 
decreasing thyroid gland vascularity. ${ }^{6,8}$ Erbil et al. showed that the addition of Lugol's solution at 10 drops/day for 10 days to conventional preoperative regimen compared to control produced lower preoperative thyroid hormone levels. ${ }^{6}$ In patients who developed adverse reactions to ATDs, Lugol's solution at 10 drops TID, together with dexamethasone and propranolol, has been shown to be effective in rapidly lowering thyroid hormones to normal or near normal depending on pre-treatment hormone levels in a case series. ${ }^{18}$ Lugol's solution alone without the addition of PTU was an option, but due to the patient's markedly elevated preoperative thyroid hormone levels, we still opted to use both medications.

Other iodine preparations can also be administered for more rapid control of thyrotoxicosis. Oral administration of iodinated radiocontrast agent (IRCA), such as iopanoic acid or ipodate, work by competitively inhibiting types 1 and 2 5 -monodeiodinase in the liver, brain and thyroid. This effectively blocks the conversion of T4 to T3, leading to rapid and constant decline of T3. Due to its iodine content, IRCAs also decrease thyroidal organification of iodine and thyroid hormone secretion from the gland, similar to Lugol's solution. ${ }^{4,5}$ However, its unavailability, particularly in certain areas in the Philippines, limits its use.

Other options for our patient are plasmapheresis, lithium and cholestyramine. Plasmapheresis is considered to be an alternative therapy for patients with thyrotoxicosis especially when conventional treatment modalities are problematic. Since most thyroid hormones are bound to plasma proteins, plasmapheresis removes protein-bound hormones from the circulation, and dilution of thyroid hormones from the intracellular compartment into the replacement solution decreases concentrations of free thyroid hormones. Its effectiveness has been demonstrated in Graves' disease, toxic multinodular goiter and iodineinduced thyrotoxicosis. ${ }^{19,20}$ Lithium is an effective alternative but is limited by its potential toxicity. The dose used in case reports for preoperative preparation is 900$1200 \mathrm{mg} /$ day for 27-67 days with serum monitoring of its level for possible toxicities. ${ }^{21}$ Cholestyramine, an ionic exchange resin, sequesters $\mathrm{T} 4$ in the intestine during enterohepatic circulation, preventing hormonal absorption and increasing fecal excretion. ${ }^{22,23}$ It is usually given at an oral dose of 4 grams 2 to 4 times a day, but lower doses have been used effectively. ${ }^{22-25}$ When added to ATDs and propranolol, thyroid hormones were decreased by the second week of treatment, but majority attained biochemical euthyroidism after 4 weeks. ${ }^{22,23}$ One reported case with resistance to conventional therapy for Graves' disease dramatically responded to the addition of cholestyramine, achieving normal thyroid hormone levels after one week of treatment. ${ }^{26}$

We considered these alternative treatments individually. Plasmapheresis was not yet available in our institution during the time the patient was admitted for surgery.
Lithium was not given due to the very high levels of thyroid hormones, and the likelihood of adverse effects with prolonged administration. Cholestyramine or other bile acid binding resins were not used, as its efficacy without ATDs has not been established. Achievement of biochemical euthyroidism can take as long as that of conventional treatment.

Our patient underwent total right thyroid lobectomy, isthmusectomy and subtotal left thyroid lobectomy. Current guidelines and a recent meta-analysis of randomized controlled trials on thyroidectomy for Graves' disease recommend near-total or total thyroidectomy as the surgery of choice, since the latter is associated with nearly $0 \%$ of recurrence of hyperthyroidism, whereas subtotal thyroidectomy may have an $8 \%$ chance of persistence or recurrence of hyperthyroidism at 5 years.,27 Our patient underwent subtotal thyroidectomy in 2009, at the time when the recommendation from the guidelines was not yet available. It was usual practice then to perform subtotal thyroidectomy, due to the concern that a more radical operation would increase complication rate. ${ }^{27,28}$ Despite diligent efforts, we could not find any record of her thyroid function test post-thyroidectomy. Given the course of an ATD-induced agranulocytosis, based on current evidence, total thyroidectomy would have been a better surgical procedure to keep the reduce the risk of recurrence.

Although contraindicated, giving another ATD should be considered as the last alternative. This carried a substantial risk, as cross-reactivity can occur as early as 11 days. ${ }^{11}$ The management was done after careful discussion with the patient, and upon her consent. At present, no risk factors have been identified to predict the occurrence of hematopoietic damage. ${ }^{11}$ As such, exploring other options should be a priority.

\section{CONCLUSION}

The medical management of hyperthyroidism is straightforward, with the use of ATDs that block thyroid hormone synthesis. In cases complicated by severe adverse events, careful consideration, analysis and selection of options for definitive management of hyperthyroid patients should be made.

\section{References}

1. Abraham P, Avenell A, Park CM, et al. A systematic review of drug therapy for Graves' hyperthyroidism. Eur J Endocrinol. 2005;153(4):489-98. http://dx.doi.org/10.1530/eje.1.01993.

2. Raboca J, Jimeno $\mathrm{C}$, Kho $\mathrm{S}$, et al for the Philippine Society of Endocrinology and Metabolism (PSEM) PhilTiDeS Working Group. The Philippine Thyroid Disorder Prevalence Study (PhilTiDeS 1): Prevalence of thyroid disorders among adults in the Philippines. J ASEAN Fed Endocr Soc. 2012;27(1):27-33. http://dx.doi.org/10.15605/ jafes.027.01.04

3. Bahn Chair RS, Burch HB, Cooper DS et al for the American Thyroid Association and American Association of Clinical Endocrinologists. Hyperthyroidism and other causes of thyrotoxicosis: Management guidelines of the American Thyroid Association and American Association of Clinical Endocrinologists.Thyroid.2011;21(6):593-646. http://dx.doi.org/10.1089/thy.2010.0417. 
4. Panzer C, Beazley R, Braverman L. Rapid preoperative preparation for severe hyperthyroid Graves' disease. J Clin Endocrinol Metab. 2004;89(5):2142-4. http://dx.doi.org/10.1210/jc.2003-031981.

5. Pandey CK, Raza M, Dhiraaj S, et al. Rapid preparation of severe uncontrolled thyrotoxicosis due to Graves' disease with iopanoic acid - a case report. Can J Anesth.2004;51(1):38-40.

6. Erbil Y, Ozluk Y, Giriş M, et al. Effect of Lugol's solution on thyroid gland blood flow and microvessel density in the patients with Graves' disease. J Clin Endocrinol Metab. 2007;92(6):21829.http://dx.doi.org/10.1210/jc.2007-0229.

7. Zhu JQ, Li ZH, Gong RX, et al. Sequential defunctionalization followed by thyroxine supplementation as preoperative preparation of hyperthyroid patients undergoing thyroidectomy. Chin Med J (Engl). 2008;121(20):2010-5.

8. Hassan I, Danila R, Aljabri $\mathrm{H}$, et al. Is rapid preparation for thyroidectomy in severe Graves' disease beneficial? The relationship between clinical and immunohistochemical aspects. Endocrine. 2008;33(2):189-95. http://dx.doi.org/10.1007/s12020-008-9076-8.

9. Nakamura H, Noh JY, Itoh K, et al. Comparison of methimazole and propylthiouracil in patients with hyperthyroidism caused by Graves' disease. J Clin Endocrinol Metab. 2007;92(6):2157-62. http://dx.doi.org/10.1210/jc.2006-2135.

10. Cooper DS. Antithyroid drugs. N Engl J Med. 2005;352(9):905-17. http://dx.doi.org/10.1056/NEJMra042972.

11. Watanabe N, Narimatsu H, Noh JY, et al. Antithyroid drug-induced hematopoietic damage: A retrospective cohort study of agranulocytosis and pancytopenia involving 50,385 patients with Graves' disease. J Clin Endocrinol Metab. 2012;97(1):E49-53. http://dx.doi.org/10.1210/jc.2011-2221.

12. Tajiri J, Noguchi S, Murakami T, et al. Antithyroid drug-induced agranulocytosis: The usefulness of routine white blood cell count monitoring. Arch Intern Med. 1990;150(3):621-4. http://dx.doi.org/ 10.1001/archinte.1990.00390150107020.

13. Toth EL, Mant MJ, Shivji S, et al. Propylthiouracil-induced agranulocytosis: An unusual presentation and a possible mechanism. Am J Med. 1988;85(5):725-7. http://dx.doi.org/10.1016/S00029343(88)80251-1.

14. Berkman EM, Orlin JB, Wolfsdorf J. An anti-neutrophil antibody associated with a propylthiouracil-induced lupus-like syndrome. Transfusion. 1983;23(2):135-8. http://dx.doi.org/10.1046/ j.15372995. 1983.23283172851.x

15. Fibbe WE, Claas FH, Van der Star-Dijkstra W, et al. Agranulocytosis induced by propylthiouracil: Evidence of a drug dependent antibody reacting with granulocytes, monocytes and haematopoietic progenitor cells. Br J Haematol. 1986;64(2):363-73. http://dx.doi.org/ 10.1111/j.1365-2141.1986.tb04130.x.
16. Tsuboi $\mathrm{K}$, Ueshiba $\mathrm{H}$, Shimojo $\mathrm{M}$, et al. The relation of initial methimazole dose to the incidence of methimazole-induced agranulocytosis in patients with Graves' disease. Endocr J. 2007;54(1):39-43. http://dx.doi.org/10.1507/endocrj.K05-068.

17. Guffy MM, Goeken NE, Burns CP. Granulocytotoxic antibodies in a patient with propylthiouracil-induced agranulocytosis. Arch Intern Med. 1984;144(8):1687-8.

18. Henley DE, Kaye JM, Nguyen HH, et al. Rapid preparation of patients with Graves' hyperthyroidism for urgent thyroidectomy. Intern Med J. 2006;36(1):63-4. http://dx.doi.org/10.1111/j.1445-5994. 2005.00988.x.

19. Ezer A, Caliskan K, Parlakgumus A, et al. Preoperative therapeutic plasma exchange in patients with thyrotoxicosis. J Clin Apher. 2009;24(3):111-4. http://dx.doi.org/10.1002/jca.20200.

20. Guvenc B, Unsal C, Gurkan E, et al. Plasmapheresis in the treatment of hyperthyroidism associated with agranulocytosis: A case report. J Clin Apher. 2004;19(3):148-50. http://dx.doi.org/10.1002/jca.20014.

21. Mochinaga N, Eto T, Maekawa $\mathrm{Y}$, et al. Successful preoperative preparation for thyroidectomy in Graves' disease using lithium alone: Report of two cases. Surg Today. 1994;24(5):464-7.

22. Tsai WC, Pei D, Wang TF, et al. The effect of combination therapy with propylthiouracil and cholestyramine in the treatment of Graves' hyperthyroidism. Clin Endocrinol (Oxf). 2005;62(5):521-4 http://dx.doi.org/10.1111/j.1365-2265.2005.02249.x.

23. Kaykhaei MA, Shams M, Sadegholvad A, et al. Low doses of cholestyramine in the treatment of hyperthyroidism. Endocrine. 2008;34(1-3):52-5. http://dx.doi.org/10.1007/s12020-008-9107-5.

24. Solomon BL, Wartofsky L, Burman KD. Adjunctive cholestyramine therapy for thyrotoxicosis. Clin Endocrinol (Oxf). 1993;38(1):39-43. http://dx.doi.org/ 10.1111/j.1365-2265.1993.tb00970.x.

25. Mercado M, Mendoza-Zubieta V, Bautista-Osorio R, et al. Treatment of hyperthyroidism with a combination of methimazole and cholestyramine. J Clin Endocrinol Metab. 1996;81(9):3191-3. http://dx.doi.org/10.1210/jcem.81.9.8784067.

26. Sebastián-Ochoa A, Quesada-Charneco M, Fernández-García D, et al Dramatic response to cholestyramine in a patient with Graves disease resistant to conventional therapy. Thyroid. 2008;18(10):1115-7. http://dx.doi.org/10.1089/thy.2008.0094.

27. Guo Z, Yu P, Liu Z, et al. Total thyroidectomy vs bilateral subtotal thyroidectomy in patients with Graves' disease: a meta-analysis of randomized clinical trials. Clin Endocrinol (Oxf) 2013;79(5):739-46. http://dx.doi.org/10.1111/cen.12209.

28. Woeber KA. Update on the management of hyperthyroidism and hypothyroidism. Arch Intern Med 2000;160(8):1067-71. http://dx. doi.org/10.1001/archinte.160.8.1067.

\section{ARTICLE COMMENTARY}

Sometimes, fortunately not very often, we are faced with a difficult decision when a patient has a severe adverse drug reaction, such as agranulocytosis, to one anti-thyroid drug, but the patient is quite ill and is still hyperthyroid. Should we switch to the other antithyroid drug to try to get the thyrotoxicosis under control, or is this too dangerous? While there are case reports of cross reactivity with both drugs leading to agranulocytosis, ${ }^{1}$ these are very rare, presumably because no one has dared do this very often.

However, despite admonitions not to use the other drug, ${ }^{2}$ it turns out that some experts are comfortable doing this, depending on the gravity of the clinical circumstances. This is especially true if only short-term ( 1 week) use is anticipated. This case report shows that this can be done safely, but I would recommend, as do the authors, to only switch to the other drug as a last resort.

Another way of rapidly controlling severe hyperthyroidism, as mentioned by the authors, is the use of cholestyramine. ${ }^{3}$

David S. Cooper, MD

Professor of Medicine

Division of Endocrinology, Diabetes, \& Metabolism

The Johns Hopkins University School of Medicine, USA

\section{References:}

1. Chen B, Lang R, Jutrin Y, Ravid M. Recurrent agranulocytosis induced by two different antithyroid agents. Med J Aust. 1983;9;2(1):38-9.

2. Cooper, DS. Antithyroid drugs.N Engl J Med. 2005;352(9):905-17.http://dx.doi.org/10.1056/NEJMra042972.

3. Sebastián-Ochoa A, Quesada-Charneco M, Fernández-García D, Reyes-García R, Rozas-Moreno P, Escobar-Jiménez F. Dramatic response to cholestyramine in a patient with Graves' disease resistant to conventional therapy.Thyroid. 2008;18(10):1115-7.http://dx.doi.org/10.1089/thy.2008.0094. 


\title{
ARTICLE COMMENTARY
}

This manuscript deals with a case of Graves' disease who developed agranulocytosis related to methimazole use. There are several points I would like to raise:

- Although self-limited, some viral infections may cause fever and profound neutropenia. Agranulocytosis related to methimazole use usually does not improve within several days even with the use of GM-CSF. At present, we do not know the exact mechanism why agranulocytosis develops after methimazole use. This is less commonly seen with the use of propylthiouracil, but it is generally recommended not to use any of these antithyroid agents once agranulocytosis occurs. In this patient, we do not know whether administration of high dose PTU would exert any beneficial effect, or if it can potentiate agranulocytosis. It would seem that control of thyroid function was possible with the use of Lugol's solution. PTU at $600 \mathrm{mg} /$ day will not control thyroid function so rapidly (i.e. within several days). If the authors administered Lugol's solution only, it would certainly control the patient's thyroid function.

- Another point is the procedure performed. Total thyroidectomy is the procedure of choice in patients with Graves' disease to permanently control recurrence of hyperthyroidism. Total thyroidectomy also confers a lesser chance of bleeding since parenchymal incision is not necessary.

This is an interesting manuscript. However, the exact description of the patient's condition at the time of agranulocytosis was not available, and the possibility that the patient might actually have some viral illness presenting with fever and neutropenia which resolved spontaneously after several days cannot be discounted.

\author{
Young-Kee Shong, MD, PhD \\ Professor of Medicine \\ Asan Medical Center, Seoul, Korea
}

\begin{abstract}
Articles and any other material published in the JAFES represent the work of the author(s) and should not be construed to reflect the opinions of the Editors or the Publisher. Authors are required to accomplish, sign and submit scanned copies of the JAFES Declaration: that the article represents original material, that is not being considered for publication or has not been published or accepted for publication elsewhere. Consent forms, as appropriate, have been secured for the publication of information about patients; otherwise, authors declared that all means have been exhausted for securing such consent. The authors have signed disclosures that there are no financial or other relationships that might lead to a conflict of interest. All authors are required to submit Authorship Certifications that the manuscript has been read and approved by all authors, and that the requirements for authorship have been met by each author.
\end{abstract}

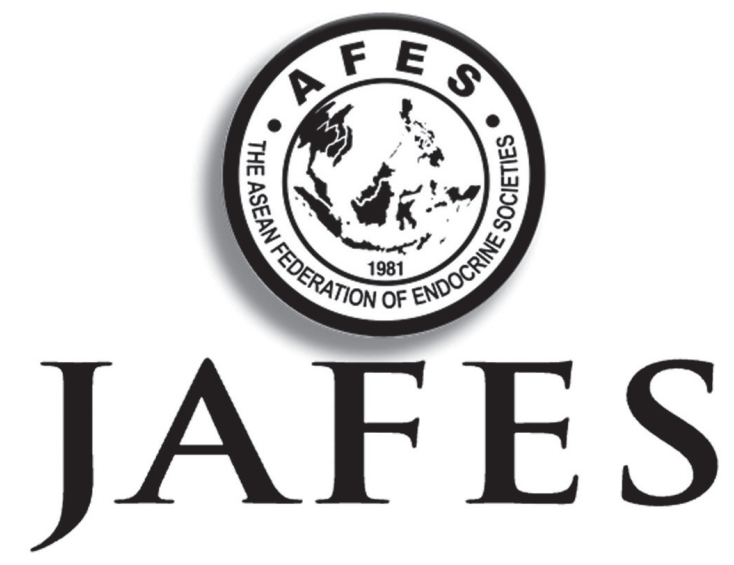

\section{Had an invigorating discussion in Grand Rounds? Share your Clinical Case Seminars at JAFES@Asia.com.}

